\title{
Aspectos da tomografia de coerência óptica na doença de Stargardt: relato de caso
}

\author{
Optical coherence tomography aspects of Stargardt's disease:case report
}

\author{
Enéias Bezerra Gouveia ${ }^{1}$ \\ Maira Saad de Ávila Morales ${ }^{2}$ \\ Norma Allemann ${ }^{3}$ \\ Guilherme Matte ${ }^{4}$ \\ Adriana Berezovsky ${ }^{5}$ \\ Juliana Maria Ferraz Sallum ${ }^{6}$
}

${ }^{1}$ Médico Estagiário do Setor de Ultra-som Ocular - Departamento de Oftalmologia da Universidade Federal de São Paulo - UNIFESP - São Paulo (SP) - Brasil.

${ }^{2}$ Mestre, Chefe do Setor de Ultra-som Ocular - Departamento de Oftalmologia da UNIFESP - São Paulo (SP) Brasil.

${ }^{3}$ Doutora, Professora Substituta do Setor de Ultra-som Ocular - Departamento de Oftalmologia da UNIFESP São Paulo (SP) - Brasil.

${ }^{4}$ Médico Estagiário do Setor de Ultra-som Ocular - Departamento de Oftalmologia da UNIFESP - São Paulo (SP) - Brasil.

${ }^{5}$ Doutora, Professora Adjunta do Setor de Eletrofisiologia Ocular - Departamento de Oftalmologia da UNIFESP - São Paulo (SP) - Brasil.

${ }^{6}$ Doutora, Chefe do Setor de Retina - Departamento de Oftalmologia da UNIFESP - São Paulo (SP) - Brasil.

Endereço para correspondência: Enéias Bezerra Gouveia. Rua Conselheiro Rodrigues Alves, 127 - Apto 111

- Bloco B - São Paulo (SP) CEP 04014-010

Email: ebgouveia@uol.com.br ou

norma.allemann@pobox.com

Recebido para publicação em 04.04.2005

Versão revisada recebida em 16.12.2005

Aprovação em 10.01.2006

\section{RESUMO}

O termo fundus flavimaculatus (doença de Stargardt) descreve um grupo de distrofias maculares hereditárias caracterizadas por múltiplos "flecks" amarelados em nível do epitélio pigmentar da retina. Os autores descrevem os achados de tomografia de coerência óptica (OCT) em paciente portador de doença de Stargardt e sugerem que a OCT tem validade como exame subsidiário no estudo das características da retina de pacientes portadores da doença de Stargardt, embora estudos envolvendo maior número de pacientes sejam indicados para permitir traçar-se o perfil das alterações mais comuns nestes casos.

Descritores: Degeneração macular; Tomografia de coerência óptica; Pigmentos da retina; Fundus oculi; Relatos de casos [tipo de publicação]

\section{INTRODUÇÃO}

A doença de Stargardt (OMIM 248200) ou fundus flavimaculatus é uma distrofia macular hereditária caracterizada por múltiplas manchas ("flecks") amareladas ao nível do epitélio pigmentado da retina ${ }^{(1)}$. É uma afecção de etiologia genética, bilateral, simétrica, lentamente progressiva, de transmissão autossômica recessiva, causada por mutações no gene ABCA4 (OMIM $601691)^{(2)}$. Seu diagnóstico geralmente é feito na primeira ou segunda décadas de vida.

Em relação aos exames complementares, a angiografia fluoresceínica é utilizada para definir mais precisamente a extensão dos "flecks" e para revelar a presença do achado associado de silêncio coroideo, que está presente na maioria dos pacientes ${ }^{(3)}$.

Vários exames são realizados na tentativa de adicionar informações sobre esta doença, e a introdução de novas tecnologias como a tomografia de coerência óptica (OCT) permitiu avaliar a retina em perfil, com resolução microscópica, dando um novo significado e enriquecimento ao estudo das diversas doenças retinianas. As imagens obtidas pela OCT tornam possível a exploração das propriedades ópticas dos tecidos, distinguindo melhor as camadas retinianas ${ }^{(4-5)}$. Este exame vem sendo empregado no diagnóstico e na monitorização de várias doenças oculares, especialmente nas maculopatias.

Os autores relatam o caso de um paciente portador de doença de Stargardt, descrevendo seus achados no exame de tomografia de coerência óptica.

\section{RELATO DE CASO}

Identificação: AD, 45 anos, masculino, branco, procedente da Bahia, com história de baixa de acuidade visual progressiva em ambos olhos há 20 

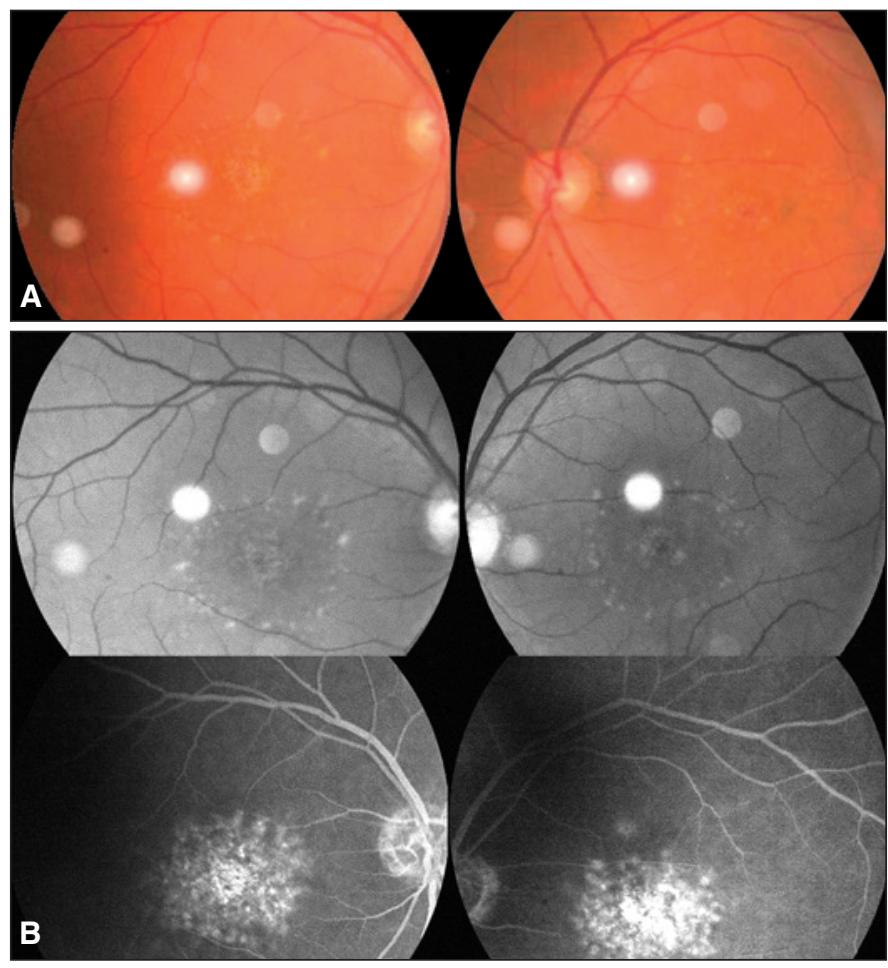

Figura 1 - A: Retinografia de ambos olhos. Observou-se atrofia do epitélio pigmentado da retina em área macular com reflexo em cobre batido e presença de lesões tipo "flecks" esparsos esvaecidos; B: Angiofluoresceinografia de ambos olhos. Imagens superiores mostram a imagem da área macular com filtro aneritra, respectivamente de olho direito $e$ esquerdo. Após injeção de contraste, observou-se hiperfluorescência por defeito em janela na área macular, com aspecto pontilhado coalescente de pontos hiperfluorescentes em ambos olhos (imagens inferiores). anos. Os antecedentes mórbidos pessoais foram irrelevantes. Os familiares não estavam disponíveis para avaliação.

Ao exame oftalmológico, o paciente apresentava acuidade visual com a melhor correção de 20/800 em ambos olhos. Reflexos pupilares fotomotor e consensual; biomicroscopia e tonometria de aplanação em ambos os olhos foram compatíveis com a normalidade.

À oftalmoscopia indireta observou-se atrofia do epitélio pigmentado da retina em área macular com reflexo em cobre batido e presença de "flecks" esparsos esvaecidos em ambos olhos (Figura 1A).

A angiofluoresceinografia demonstrou hiperfluorescência por defeito em janela nas áreas descritas anteriormente, com aspecto pontilhado coalescente de pontos hiperfluorescentes tardios (Figura 1B - imagens inferiores).

O exame de eletroretinograma (ERG) de campo total apresentou amplitudes pico-a-pico e tempo de culminação da onda-b de bastonetes normais em ambos olhos. As amplitudes de respostas de cones mostraram-se subnormais com tempos de culminação normais em ambos os olhos (Figura 2). As respostas de cones na região macular, obtidas pelo ERG focal, mostraram-se reduzidas em ambos olhos.

Ao exame da tomografia de coerência óptica de ambos os olhos pôde-se observar uma área de depressão foveal maior que correlaciona com a área de atrofia com reflexo em cobre batido visível nas retinografias. Cálculo de espessura foveal central estimada pela OCT foi de 143 micra no olho direito e 165 micra no olho esquerdo (Figura 3 ).

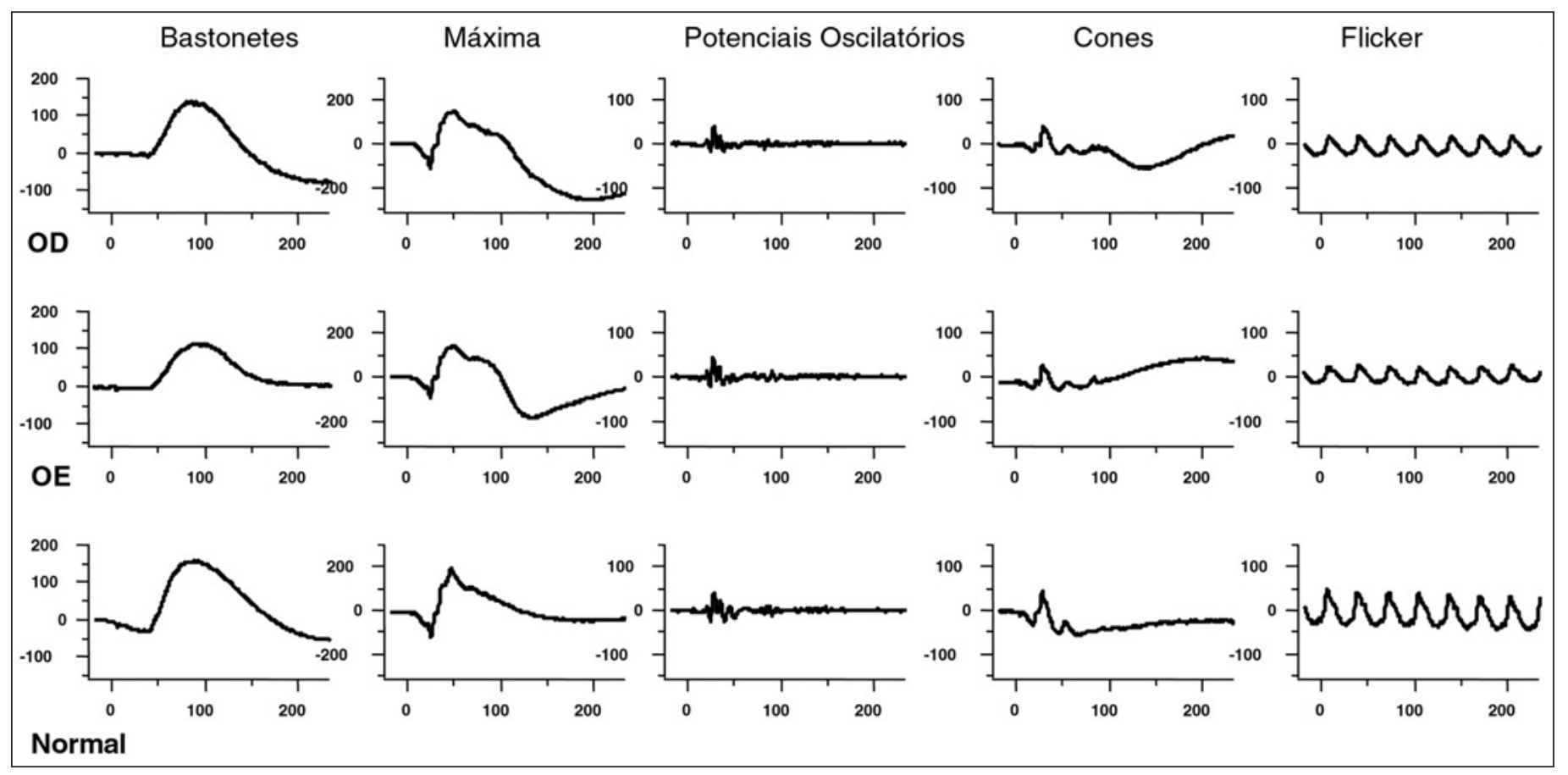

Figura 2 - Eletrorretinograma (ERG) de campo total do olho direito (painel superior), esquerdo (painel central) e de um sujeito normal (painel inferior) com idade semelhante. As respostas escotópicas de bastonetes, máxima resposta, potenciais oscilatórios, são seguidas de respostas fotópicas de cones e $30 \mathrm{~Hz}$ flicker, com amplitude $\mu \mathrm{V}$ (eixo-Y) e tempo em ms (eixo-X). 

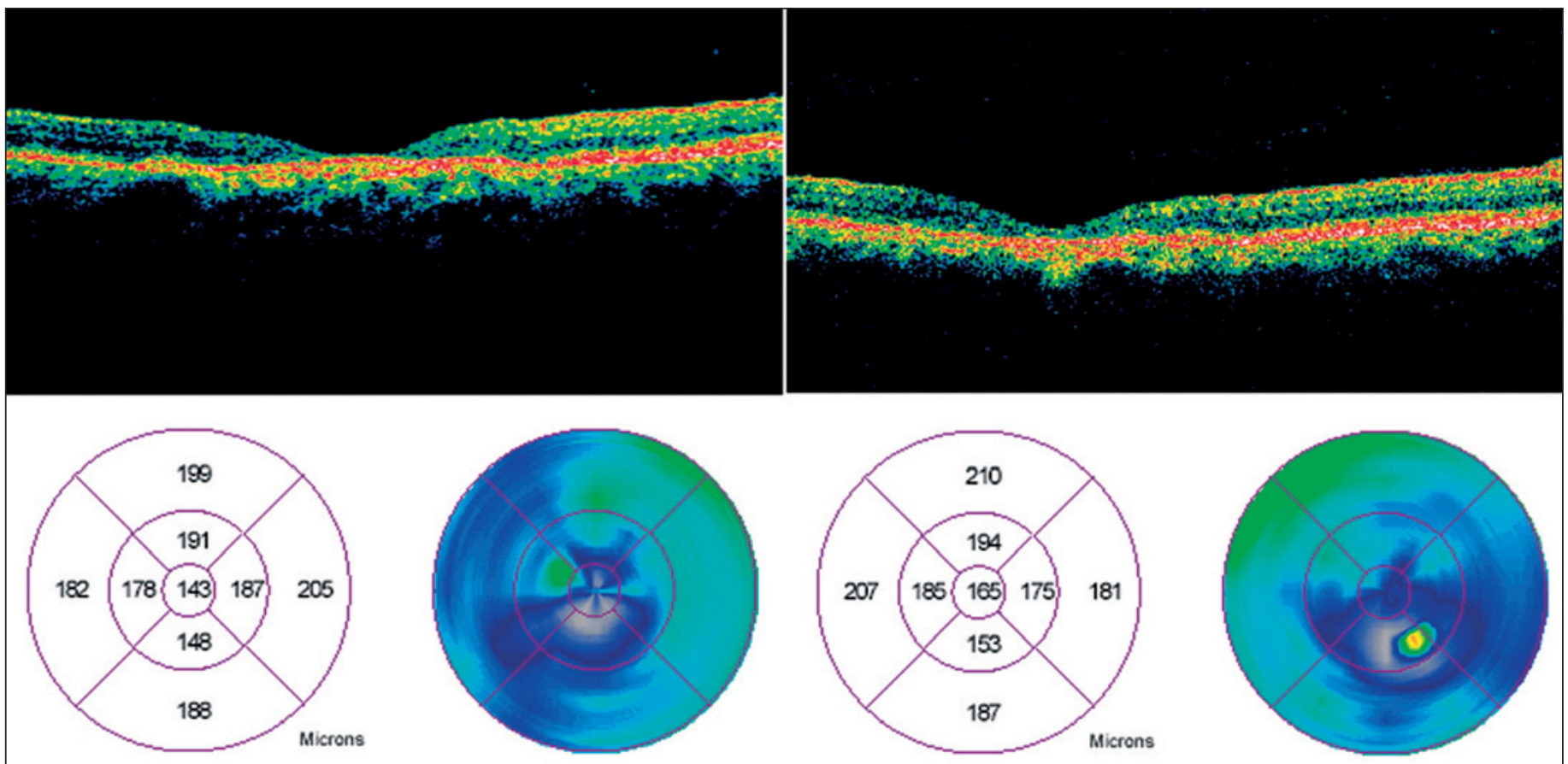

Figura 3 - Tomografia de coerência óptica (OCT). Corte óptico da região macular revela depressão foveal aumentada em ambos olhos. Espessura foveal central estimada pela OCT com 143 micra no olho direito e 165 micra no olho esquerdo.

\section{DISCUSSÃO}

A doença de Stargardt é a distrofia macular hereditária mais comum, representando $7 \%$ das distrofias retinianas ${ }^{(6)}$ e também a distrofia macular hereditária recessiva mais freqüente ${ }^{(7)}$. A primeira e única manifestação clínica é a diminuição da visão central, que predominantemente se inicia entre os seis e quinze anos de idade, podendo, em casos excepcionais, a exemplo do nosso relato, iniciar os sintomas na terceira década de vida.

Os achados no fundo de olho dependem da forma de apresentação e cursos clínicos da doença, podendo em alguns casos de pacientes com mais idade como o descrito, os "flecks" esvaecerem e a atrofia do epitélio pigmentado da retina (EPR) aumentar( ${ }^{(8)}$. Nas fases avançadas, a acuidade visual varia entre 20/200 e 20/400 ${ }^{(3)}$, que é a atual situação do paciente apresentado. Tivemos o cuidado de fazermos o diagnóstico diferencial do nosso paciente com outras doenças maculares com início na juventude, que incluem: retinosquise ligada ao $\mathrm{X}$; distrofia macular viteliforme; distrofia progressiva de cones; drusa familiar; e fundus albipunctatus.

Todos os acometimentos maculares de origem coroidiana e retiniana apresentam quadro de atrofia com repercussões funcionais e elétricas semelhantes à doença de Stargardt. Embora não fosse possível a avaliação dos membros da família do paciente por nós apresentado, os achados clínicos, angiofluoresceinográficos e eletrofisiológicos foram característicos para o diagnóstico da doença de Stargardt.

Muitos estudos têm tentado definir parâmetros de evolução da degeneração, no entanto, os exames existentes utiliza- dos, como a angiografia fluoresceínica e o eletrorretinograma, não avaliam a espessura retiniana. A OCT fornece imagens de alta resolução, mostrando ser de grande auxílio na avaliação de doenças maculares, uma vez que é possível quantificar, de modo objetivo e preciso, a espessura retiniana auxiliando assim no diagnóstico e acompanhamento ${ }^{(9-10)}$.

No caso relatado, a zona de atrofia macular secundária à degeneração do EPR é demonstrada na angiofluoresceinografia como um defeito em janela e na OCT como uma depressão foveal aumentada. Estes indícios de atrofia macular explicariam a baixa visual progressiva, bem como corresponderiam aos dados da literatura que consideram a descrição de atrofia do EPR associada à degeneração dos fotorreceptores na etiopatogenia da doença de Stargardt.

\section{CONCLUSÃO}

Demonstramos através da OCT que na doença de Stargardt existe uma depressão foveal maior, embora estes achados não possam ser considerados ainda como característicos para esta doença, uma vez que se trata da descrição de um único relato de caso, eles podem complementar a interpretação do raciocínio diagnóstico, de modo que a OCT teria validade como método coadjuvante no diagnóstico de pacientes portadores da doença de Stargardt, no entanto, necessita de estudos prospectivos adicionais, com maior número de pacientes, período de acompanhamento longo, avaliação das diversas formas de apresentação, tentando assim correlacionar os achados nos diferentes exames disponíveis fornecendo dados para um entendimento 
mais completo do mecanismo fisiopatológico envolvido. A partir de então poderíamos traçar o perfil das alterações mais encontradas pela OCT tornando possível a utilização deste exame para o acompanhamento evolutivo do caso.

\section{ABSTRACT}

The term fundus flavimaculatus (Stargardt disease) describes a group of inherited macular dystrophies characterized by multiple yellow to yellow-white flecks at the level of the retinal pigment epithelium. The authors describe findings in the patient with Stargardt's disease using optical coherence tomography (OCT), and suggest the examination to be valid as subsidiary method in the study of the characteristics of the retina in Stargardt's disease patients, but studies involving a series of patients should be able to show the most frequent findings in these cases.

Keywords: Macular degeneration; Tomography, optical coherence; Retinal pigments; Fundus oculi; Case reports [publication type]

\section{REFERÊNCIAS}

1. Zhang K, Kniazeva M, Hutchinson A, Han M, Dean M, Allikmets R. The ABCR gene in recessive and dominant Stargardt diseases: a genetic pathway in macular degeneration. Genomics. 1999;60(2):234-7.

2. Allikmets R, Singh N, Sun H, Shroyer NF, Hutchinson A, Chidambaram A, et al. A photoreceptor cell-specific ATP-binding transporter gene (ABCR) is mutated in recessive Stargardt macular dystrophy. Nat Genet. 1997;15(3):236-46. Erratum in: Nat Genet. 1997;17(1):122.

3. Fish G, Grey R, Sehmi KS, Bird AC. The dark choroid in posterior retinal dystrophies. Br J Ophthalmol. 1981;65(5):359-63.

4. Huang D, Swanson EA, Lin CP, Schuman JS, Stinson WG, Chang W, et al. Optical coherence tomography. Science. 1991;254(5035):1178-81.

5. Ostrosccki MR. Tomografia em retina In: Rodrigues Alves CA. Neuroftalmologia. São Paulo: Roca; 2000. p.333-42.

6. Unonius N, Farah ME, Sallum JMF. Classificação diagnóstica dos portadores de doenças degenerativas de retina, integrantes dos grupos Retina São Paulo e Retina Vale do Paraíba. Arq Bras Oftalmol. 2003;66(4):443-8.

7. Blacharski, PA. Fundus flavimaculatus. In: Newsome DA, editor. Retinal dystrophies and degenerations. New York: Raven Press; 1988. p.135-59.

8. Fishman GA, Farber M, Patel BS, Derlacki DJ. Visual acuity loss in patients with Stargardt's macular dystrophy. Ophthalmology. 1987;94(7):809-14.

9. Gaudric A, Haouchine B, Massin P, Paques M, Blain P, Erginay A. Macular hole formation: new data provided by optical coherence tomography. Arch Ophthalmol. 1999;117(6):744-51.

10. Coker JG, Duker JS. Macular disease and optical coherence tomography. Curr Opin Ophthalmol. 1996;7(3):33-8.

\section{Curso de Afualizagão em Oftalmologia do Instifuto CEMA*}

\section{9 de Dezembro de 2006}

\section{Auditório do Hospital CEMA São Paulo - SP}

\section{INFORMAÇG̃E5: Tel.: (11) 6602-4034}

